\title{
THE INDISPENSABILITY OF GOOD OPERATION \& MAINTENANCE (O\&M) MANUALS IN THE OPERATION AND MAINTENANCE OF LOW CARBON BUILDINGS
}

\author{
Owajionyi L. Frank*, Siddiq A. Omer, Saffa B. Riffat, Blaise Mempouo \\ Architecture, Climate \& Environment (ACE) Research Group \\ Department of Architecture \& Built Environment, University of Nottingham, UK. \\ Corresponding Author: *laxolf@nottingham.ac.uk (+44(0)7831 982 350)
}

\begin{abstract}
Increase in energy usage, particularly from fossil fuel sources is widely understood to be responsible for the environmental problems (Climate Change) experienced globally today. Response to mitigating this anthropogenic induced consequence created the need for innovative low carbon and renewable technologies in buildings. In the UK presently, every new building is expected to be low-carbon and energy-efficient. However, it is widely acknowledged that significant differences often exist between designed and in-use performances of the buildings. Clients and end-users of these technologies appear not to be getting long term value for their investments; much attention has not been given to how these innovative technologies can be operated and maintained long into the future. Recent researches also underpin the fact that the wide information gap existing between designers and building end-users is one of the factors responsible for the performance-gap. This paper therefore presents excerpts of a research aimed at exploring a best practice approach to operability and maintainability of low-carbon-buildings. The research methodology involved the use of interviews, surveys and case study. Findings suggest that a properly prepared O\&M manual is a potential document that that could bridge this gap and that it is an indispensable tool for the effective and efficient operation and maintenance of low carbon buildings.
\end{abstract}

Keywords: Design Stage; Low carbon buildings; O\&M Manuals; Operation and Maintenance

\section{$1.0 \quad$ INTRODUCTION}

Climate change has been identified as the greatest challenge confronting human society in this $21 \mathrm{st}$ century (RIBA, 2009a). Human activities have also been fingered as having both direct and indirect impacts on the climate. The climate consequently impacts on the economic and social activities, as well as health, wellbeing, safety and demands for resource use (BRE, 2009). RIBA (2009a) also affirms that there is an overwhelming scientific consensus indicating that climate change is a consequence of greenhouse gas emissions resulting from anthropogenic (human-induced) activities; such as operating buildings, travelling, extracting resources and industrial manufacturing.

Literature sources identified the deployment of energy efficient measures and a switch to new and renewable sources of energy as sustainable approach to attaining the reduction in greenhouse gas emissions (Hensen and Lamberts, 2011; Adshead, 2011). In the built environment this development has led to varying and continued innovation of low carbon and renewable technologies, which are also referred to as sustainable technologies, green technologies or clean technologies. These measures are adopted to meet up with the World scientific consensus on a Carbon emissions target of $80 \%$ reduction by the year 2050 (Avis, 2011) and to keep global warming below its dangerous level 
(Nana and Stokes, 2012). Consequently, building designers were being faced with the challenge of how to ensure that the new buildings they design and the existing buildings they refurbish emit dramatically less $\mathrm{CO}_{2}$ than has been in the past decades. Low carbon buildings (LCBs) are aimed at producing significantly lower carbon dioxide emissions than others (RIBA, 2009c).

However, there is widespread belief across government and within industry that construction underperforms in terms of its capacity to deliver value (Cabinet Office, 2011). Clients and end-users of these buildings appear not to be getting long term value for their investments. Much attention has also not been given to how these new and innovative technologies can be operated and maintained long into the future. Recent researches also have suggested that significant differences often exist between the design and in-use performance of buildings, and that the wide information gap existing between designers and end-users of buildings is one of the factors responsible for the significant disparity in performance (Malekzadeh et al, 2011; Birchall, 2011).

This paper identifies properly prepared building operation and maintenance $(\mathrm{O} \& \mathrm{M})$ manuals, as potential documents that could be harnessed to bridge this information gap and ensure that LCBs are operated and maintained long into the future. The Building O\&M Manual is a document that guides the building owner/developer, property manager and/or the users on how to organize the repair and maintenance of the fabric of a building, its services and surrounds effectively and economically. It also directs on the efficient day to day cleaning of the building and directs its user(s) on the efficient operation of its services (MPBW, 1970). However, in the UK the O\&M manuals seem not to be meeting its required purposes; in most cases, they are prepared after the buildings had been built and occupied, and often, by a team that was not involved in the design process (AHDA, n.d.) and just to fulfil the legal requirements and not fit for purpose. The construction industry has been described by the Building Services Research and Information Association (BSRIA) as having a poor reputation when it comes to O\&M manuals, in terms of quality and timeliness of delivery (BSRIA, 2011).

LCBs are buildings that use significantly less energy and emit less carbon compared to regular buildings, as well as provide comfortable and productive spaces (Carbon Trust, 2012). They are also fitted with unconventional technologies, thus requiring unconventional methods of operation and maintenance. The need for end-users to be guided through the workings of the unconventional systems cannot be overemphasised. Literature sources have indicated that occupants behaviour or 
'people factors' as described by James E. Piper, bear greatly on the building performance (Yu et al, 2011; Masoso and Grobler, 2010; Piper, 1999). Yu et al (2011) reported a study by Ouyang and Hakao (2009) which investigated energy-saving potential by improving user behaviour using 124 households in China. The 124 houses were divided into two groups; one group was educated to promote energy-conscious behaviour and adopt corresponding energy saving measures, while the second group not educated, they were expected to keep the status-quo. The result showed that 'effective promotion of energy-conscious behaviour could reduce energy consumption by more than $10 \%$. This implies that the way the systems are operated by the occupants impacts on the energy performance, and that providing guidance to occupants on how the systems could be efficiently operated is capable of improving on general performance of systems. So a well-documented operational procedure in the form of an O\&M manual becomes imperative.

This paper therefore discusses how the O\&M manual could be improved upon, to meet its required purposes of aiding effective and efficient operation and maintenance and communicating the design intent of the designers to the end-users of LCBs in particular; thereby bridging the information gap between the design team and the end-users.

\subsection{BACKGROUND TO RESEARCH}

\subsection{The imperatives for O\&M Manuals in Low Carbon Buildings}

The O\&M manual was introduced to the UK by the report of The Committee on Building Maintenance published in the Research and Development Bulletin of Ministry of Public Building and Works of September 1970. The purpose of the O\&M manual as contained in the committee's submissions included:

1) It will enable the property manager to organise the repair and maintenance of the building, its services and surrounds effectively and economically;

2) It will enable the occupier to clean and operate its services efficiently and reduce losses of time and production;

3) It will establish a link between the project design team and the client and his maintenance organisation to their mutual benefit. 
A fourth purpose of the O\&M manual was also highlighted in Blacker (1994) and CIRIA (1999) which requires that a good O\&M manual needs to provide basis for improved future design through lessons learnt from previous projects.

A properly prepared and comprehensive O\&M manual will provide link between the design team, the client and the operation \& maintenance organization to their mutual benefits (MPBW, 1970). This link will also provide useful information that will be handy and useful for Post Occupancy Evaluation, Condition Survey and by extension, 'the next design'. By this, many of the faults which tend to be repeated in new designs will be averted (Seeley, 1987).

In the United Kingdom and a few other countries in Europe, Australia, United States of America (USA) and in the Caribbean, the use of O\&M has become popular and made a legal component of building delivery documentations. It is a form of long term maintenance plan for the specific building it is made. It is also an updatable document, particularly with change in use and ownership (CIRIA, 1999). Some of the benefits of a properly prepared O\&M manual according to CIRIA (1999) include:

1) Producing significant benefits when it is used as the basis for timely, correct and efficient building maintenance, operation and planning

2) Better designed and constructed buildings resulting from project team members' improved understanding of operational and maintenance requirements to meet the design life specified for the building.

3) The ready availability of information for components, eg life expectancy.

4) A proper understanding by the occupants, of purpose and use of the building.

5) Retaining the value of the building as a result of better maintenance

6) A reduced level of disruptive and costly effects of breakdown or failure.

Silva et al (2004) and Blacker (1994) posits that the development of O\&M Manuals will facilitate the proper maintenance of the buildings throughout the life cycle and also influence the architect in the decision-making process.

\subsection{Legal Requirements for Building O\&M Manuals in the UK}

In the UK, it has become a 'legislative must' since 1974 for owners of buildings to be provided with information on how to safely and efficiently operate and maintain building services (BSRIA, 2007). This is supported by the provisions of Sections 3 and 6 of the Health and Safety at Work Act 1974, as 
amended by the Consumer Protection Act 1987 (lbid). By the Act as amended, designers, manufacturers and importers or suppliers of plant and systems are duty bound to provide adequate operating information for the occupants that will enable them operate the plants or systems in safe manner and so that they are not injurious to health when in use (Ibid).

Section 3 of Part L1A and L2A of the Building Regulations for England and Wales also highlighted on the imperative for owners of buildings to be provided with sufficient information about the building, fixed building services and their maintenance requirements so that the building can be operated in a manner as to use no more fuel and power than is reasonable in the circumstances.

The Statutory Instruments (2007 No.320) establishing the Construction (Design and Management) Regulations 2007 (CDM) requires designers to take all reasonable steps to provide with their designs sufficient information about aspects of the design of the structure or its construction or 'maintenance' as will adequately assist clients, other designers and contractors to comply with their duty under the Regulations. Other primary instruments supporting this requirement include:

1) Construction (Design and Management) Regulations 2007 Approved Code of Practice (APCoP)

2) BS 4884: Part 3: 1993 Technical Manuals - Guide to presentation.

\subsection{METHODOLOGY}

The results presented in this paper were informed by semi-structured interviews populated by highly experienced professionals involved with procurement, design, management or research of low carbon buildings in the UK. They are mostly persons who sit at the top management levels of their respective organisations, and having more than 30 years of experience in their respective fields of practice. Other methods adopted in building up the data include web-based and hard-copy surveys. While the web-based survey was populated by nearly $70 \%$ design professionals, the hard-copy survey was populated by $50 \%$ facilities managers. In both cases the population cut across a variety of building professionals drawn from private consulting and contracting firms, public client bodies, academic/research bodies and construction charity organisations. All participants in the web-based survey were also involved with procurement, design, management or research of low carbon buildings in the UK. 
One of the objectives of the study was to make in-depth probe into the maintainability ethos in the UK. So the interview questions were designed in a semi-structured format, with structured open ended questions. It allows participants the flexibility of expressing themselves in their own words. The data were analysed using the thematic content analysis method discussed in Burnard (1991), Aronson (1994) and Schwandt (2007). This involved coding the data by themes drawn from existing theoretical knowledge (deductive coding) and from the data itself (inductive coding). The deductive themes were based on the set objectives of the interviews. This method of analysis also involved some numerical analysis; what is referred in literature as partial quantitative method (Julien, 2008); providing room for systematic qualitative analysis with clear procedures for checking the quality of the analysis conducted.

The online survey was designed in a structured format involving multiple-choice and ranking questions, using feedbacks from the interviews. It was intended to reach a wider population of participants and also to allow for quantitative analysis of data. It was also designed to complement the results of the interviews. There were relatively poor response of facilities managers in both the interviews and web-based survey. Considering their roles in the direct day-to-day management buildings, it became necessary to design a hard-copy questionnaire and circulated at the annual conference of British Institute of Facilities Managers (BIFM) - 'ThinkFM 2012', and also at the Nottinghamshire Construction Forum (NCF). Both surveys were analysed quantitatively and the open ended comments were analysed using the thematic content analysis methods.

\subsection{RESULTS AND DISCUSSIONS}

\subsection{The Construction Industry's Reputation with regards to O\&M Manuals in the UK} Literature sources (BSRIA, 2011; Silva et al, 2004; CIRIA, 1999) have revealed that despite the huge benefits attributed to the O\&M manual and its legislative requirements, the manual has continued to fail in meeting its expected requirements. In section 2.2, it has been established that it is a "legislative must' for owners of buildings in the UK to be provided with information on how to safely and efficiently operate and maintain building services. Findings from literature and preliminary investigations have also revealed that the O\&M manual has continued to fail in meeting its expected requirements as a tool for safe, healthy and efficient operation and maintenance of buildings. In July 2011, BSRIA asserts that construction industry has a poor reputation with regards to O\&M manual quality and 
timeliness of delivery, based on findings from its ten year research on the key performance indicators for building services contractors (BSRIA, 2011).

At the interview stage of this study, some of the interviewees expressed the opinion that suggests that the O\&M has not been able to meet the needs of users and operators of the buildings; in most cases they find it difficult to use. Quoting one of the interviewees:

We've done building before, when they are finished we handed over the O\&M manual and six months later we get a phone call saying; what do we do with this?"

The question from this client suggests that the manual was not in a form they could identify with or understand. Imagine that you buy a car and you are handed the car manual and you ask, 'what do I do with this'? This typical client definitely may not have a good impression about O\&M manuals and may not be able to benefit from its inherent benefits.

\subsection{Why the Poor Reputation of the Industry with O\&M Manuals}

In this study, participants in the surveys were asked to identify reasons responsible for this poor reputation. As presented in figure 1, the results from the web-based survey show that the top reason for this poor reputation is that 'most O\&M manuals lack appropriate details that could aid effective operation and maintenance', as identified by $50 \%$ of the participants. Other top reasons; each identified by $37.5 \%$ of the participants are:

1) The manuals are just compilations of manufacturers' manuals

2) They are being provided just for legal purposes and not fit for purpose

3) The time of delivery does not aid maintainability.

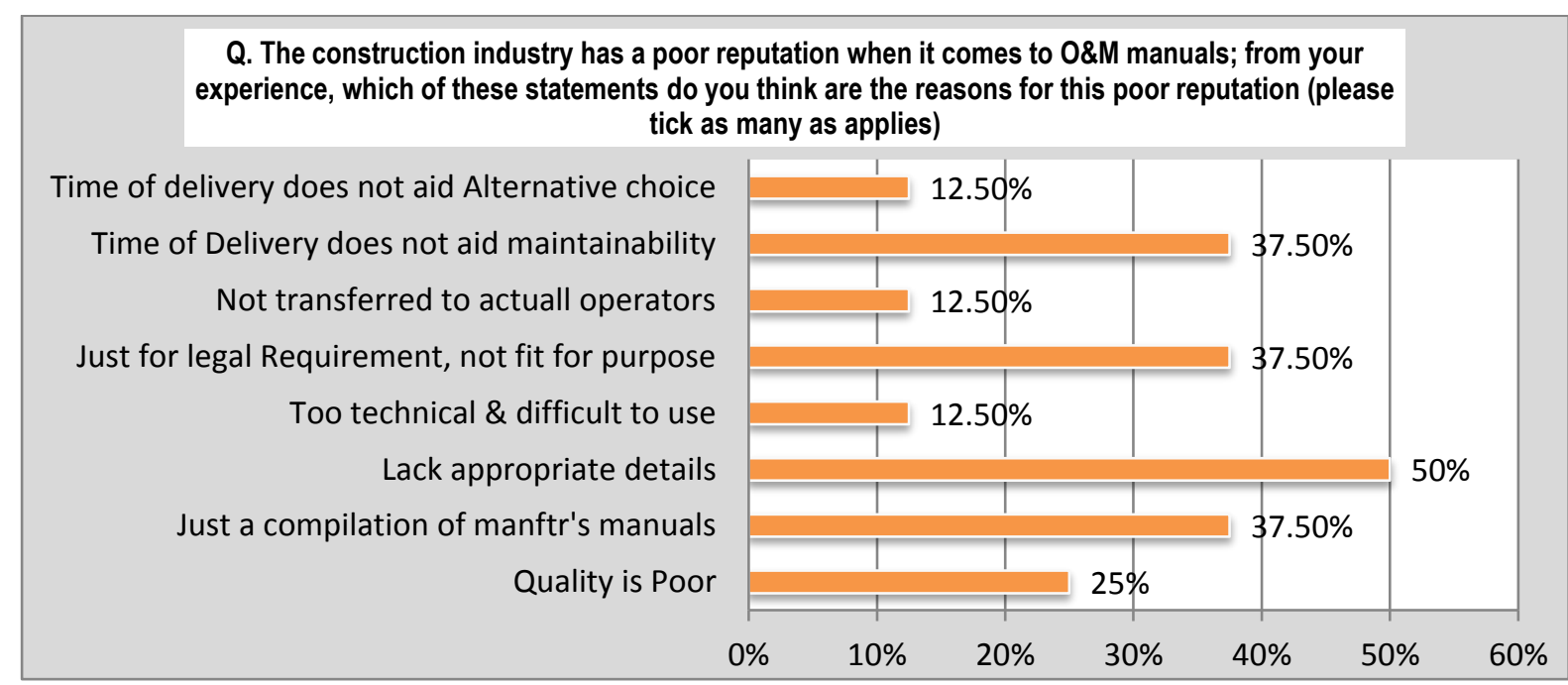

Figure 1: Possible Factors Responsible for the Poor Reputation of the O\&M Manual in the Building Industry (Online Survey) 
In the second survey which was specifically aimed at understanding practitioners' opinions about the O\&M regime, the question was reframed in a rating scale format. Participants were asked to rate the level of their agreement or disagreement with the factors outlined on the questionnaire, as being responsible for the poor reputation O\&M manuals attract to the industry. The rating was on a scale of $1-5$ where 1 is 'strongly disagree' and 5 - 'strongly agree'. From the result, most participants who are mostly facilities managers rated 'Just a compilation of manufacturers' manuals' to be the top reason why the O\&M manuals attract poor reputation to the industry. The rating average for this option was 4.29 out of 5 as shown on figure 2 .

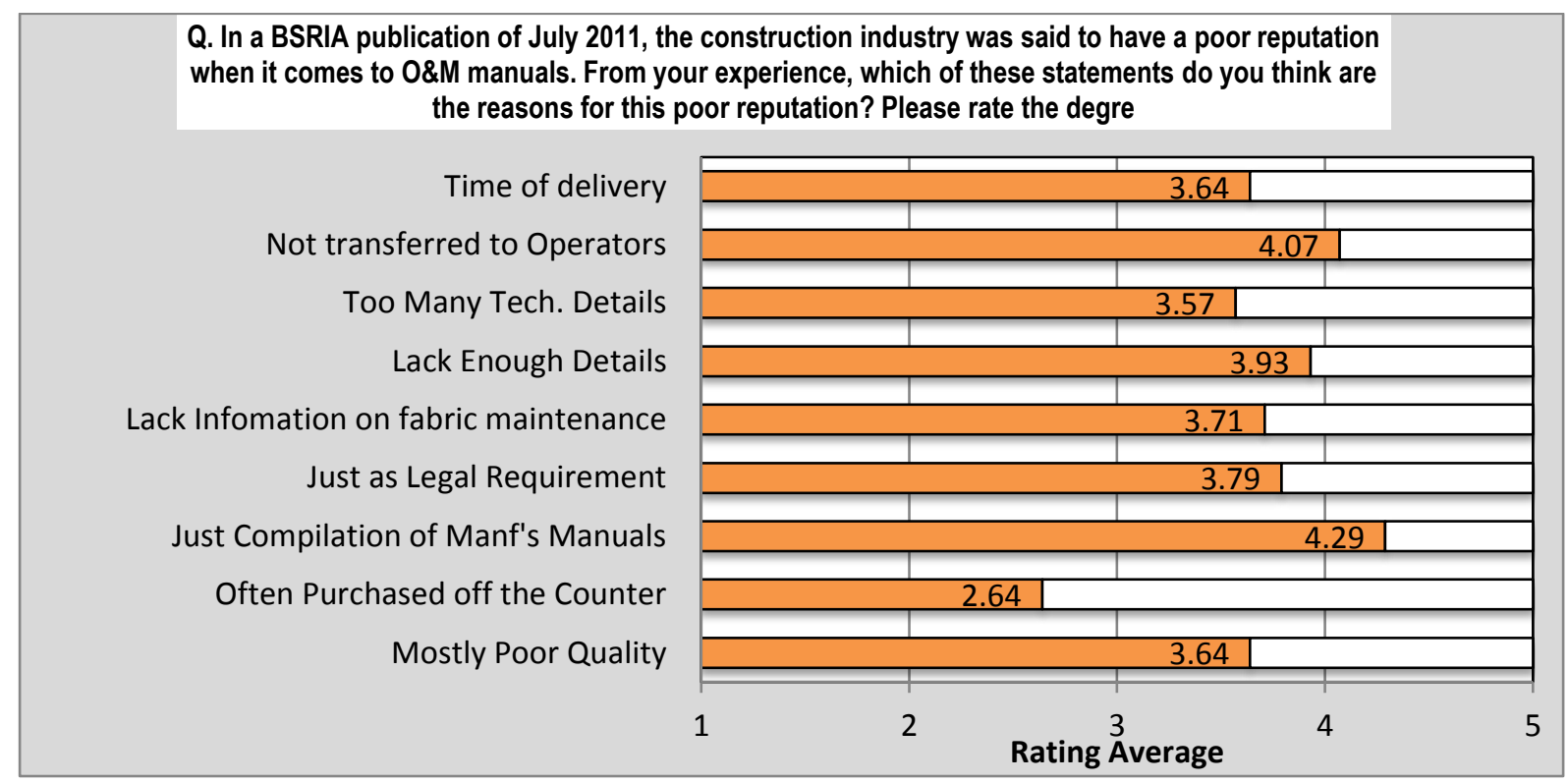

Figure 2: FM Professionals Perception of Possible factors Responsible for the Poor Reputation of the O\&M Manual in the Building Industry (Hard Copy Survey)

However, there are other factors that were rated above average by the participants as see in figure 2 . They include:

- Not usually transferred to building operators in case of renting and change of ownership

- Lack appropriate details that could aid efficient maintenance

- Prepared just as a legal requirement, and not fit for purpose

- Contains too many technical details that not easily understood

- Etc.

Respondents were also asked to comment freely about the O\&M manual regime in the UK. 
In all, a total of ten factors have been identified as being responsible for the poor repute O\&M manuals have attracted to the industry, based on the finding of this study. They are summarised in table 1.

Table 1: Factor Affecting the Construction Industry's Reputation about O\&M Manuals

\begin{tabular}{|l|l|}
\hline S/n. & Factors \\
\hline 1 & Most O\&M manuals lack enough details that could aid effective operation and maintenance \\
\hline 2 & Most O\&M manuals are just compilations of manufacturers' manuals \\
\hline 3 & Most O\&M manuals are prepared just for the purpose of meeting legal requirements and not fit for purpose \\
\hline 4 & The time of delivery does not aid maintainability \\
\hline 5 & The manuals in most cases are not transferred to the actual operators in case of lease or re-sale of property \\
\hline 6 & Most O\&M manuals lack information about the building fabric \\
\hline 7 & $\begin{array}{l}\text { The Time of delivery does not give clients opportunity of alternative choice of materials, equipment and/or } \\
\text { technology }\end{array}$ \\
\hline 8 & The quality of most O\&M manuals is poor \\
\hline 9 & Most O\&M Manuals contain too many details and technicalities that make them too difficult to be useable \\
\hline 10 & Most O\&M Manuals are not user-friendly \\
\hline
\end{tabular}

\subsection{Current Practices with respect to O\&M Manual Delivery Process}

During the preliminary studies and the interview stages it was noted that most O\&M manuals were being produced not as a necessity for the project, but as an unnecessary and painful legal requirement that must be met. So at the end of the projects, contractors grudgingly gather every document they have received from suppliers and sub-contractors into file, as an O\&M manual. In the words of one of the interviewees, he said:

"What a contractor does at the end is that he gets a young member of staff to photocopy everything he ever received about everything in the building and he very kindly puts it in a series of ring binders folders for you. If you're lucky, you get an index, but finding things and getting that information from the O\&M manual is very painful. .... So I see the industry does have a poor reputation. The contractor thinks if he hands the building over and he gives you all these files, then he think he has done his job. That is poor in my view" (Interviewee 003).

As part of general comments about the O\&M manual in the hard copy questionnaire, one of the respondents noted thus:

"Too often left to the construction team; seen as an unnecessary burden to them when they are trying to complete the build".

Further findings from the study also revealed that there are 'Specialist O\&M Manual Editors (Blacker, 1994; People4Business, 2010; WebFm, 2010), who are usually neither in the designers nor contractors teams. In most cases they come in towards the end of the construction stage, when all equipment and machineries may have been installed, sometimes when the building is being prepared for handing over and commissioning. Figure 3 shows the results from the online survey. The question sought to know at what stage of a typical building project the first and final drafts of the O\&M are 
usually prepared. It shows that preparation of the first draft of the manual is usually commenced from the construction or during handover and commissioning stage of the project. The final draft is then produced while the building is in operation or during handover/commissioning and in few cases, still within the construction period.

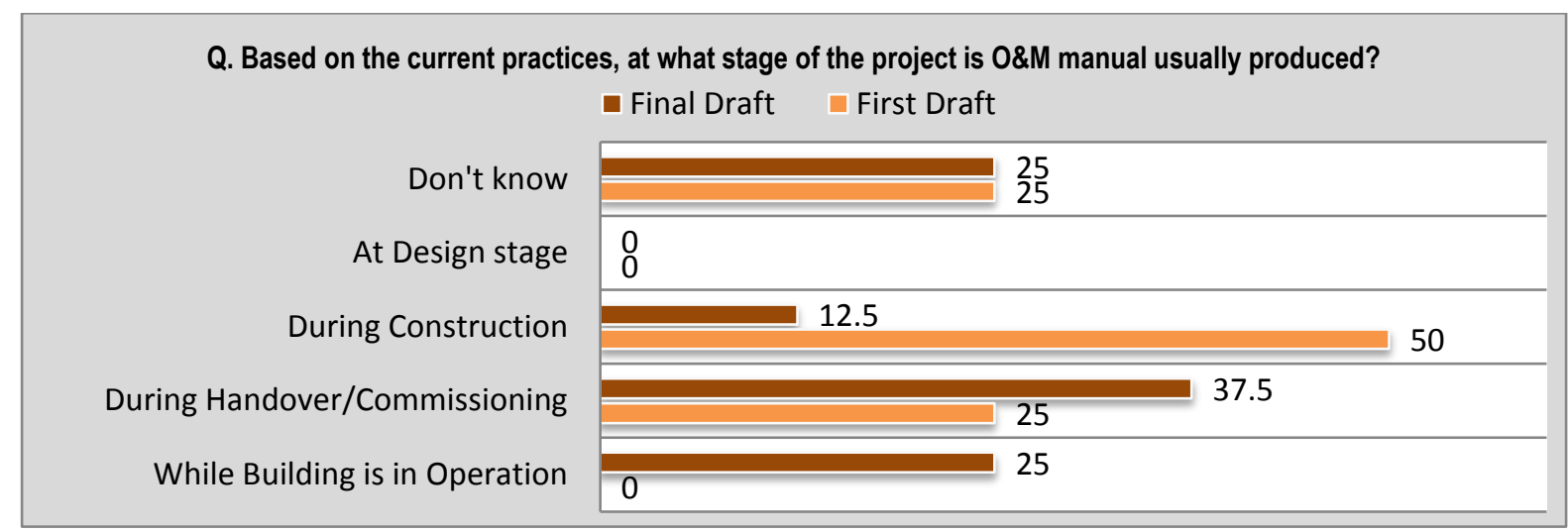

Figure 3: The stage of Construction when the O\&M manual is usually produced, based on current practices (Online Survey)

The disparity noticed in the time O\&M manuals drafting commences shows that there is disparity in the time of delivery. This also indicates that there was no standard procedure on when the manual drafting commences and when it should be delivered. Comments from interviewees and the survey participants, as noted in section 4.3 , indicates that contractors grudgingly compile the manual when they are trying to complete the build. This corroborates the result in figure 3 which shows that $37.5 \%$ and $25 \%$ of the participants respectively indicated that the final drafts are usually produced during Handover/commissioning and while the building is in operation. By this time, making alternative choice for a system which operation and maintenance regime have been found challenging may be difficult.

\subsection{Why a Good O\&M Manual is Indispensable for LCBs}

The indispensability of the benefits of a good O\&M in the operation and maintenance of buildings generally has been discussed in section 2.1. References were made to Blacker (1994), CIRIA (1999) and Silva et al (2004). However, there was no evidence found that their assertions have been subjected to empirical testing. The benefits of a properly prepared O\&M manual discussed in section 2.1 could be summarised to mean that 'if properly prepared, the O\&M manual can act as a bridge to the existing gap between designers and operators of buildings. So participants in the online survey 
were asked to rate the extent of their agreement/disagreement to this statement. The result returned $100 \%$ of the respondents agreeing or strongly agreeing to the statement as shown in figure 4 .

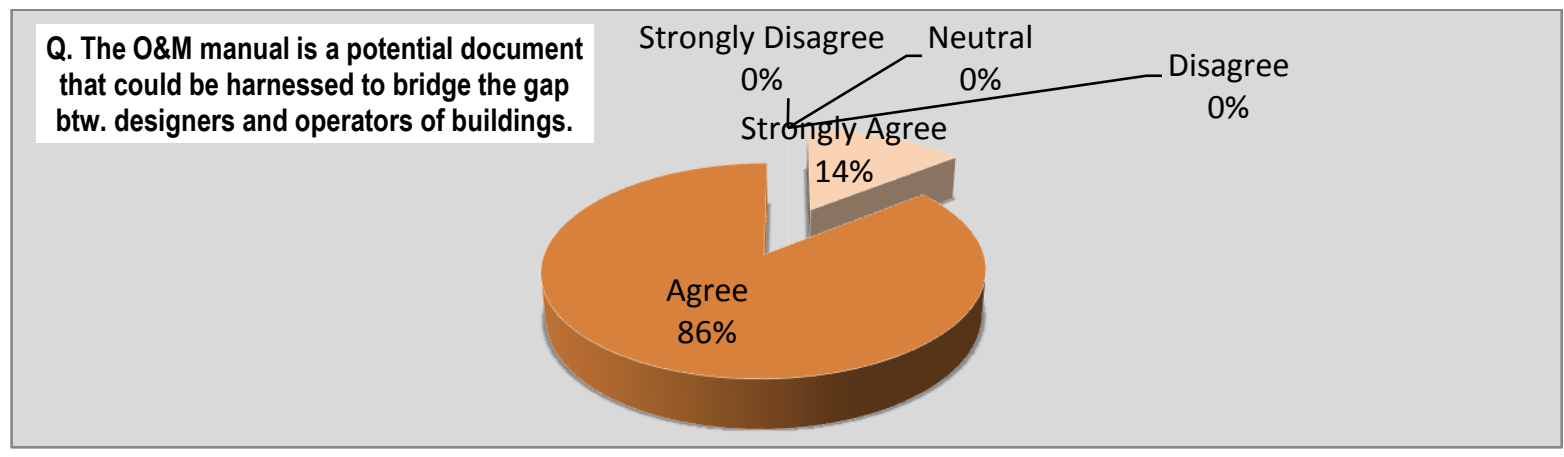

Figure 4: Practitioners' Opinion about O\&M Manual as a Potential Document that could be harnessed to bridge the gap btw. Designers and Operators of LCBs (Online Survey)

This indicates that if the gap between designers and operators of buildings needs to be bridged, then a properly prepared O\&M manual is indispensable, and more so for buildings with unconventional, new and innovative technologies. Corroborating this statement, the hard copy survey respondents who are mostly facilities managers were asked to rate how well they agree/disagree with the statement that 'a well prepared O\&M manual is indispensable for the operation and maintenance of low carbon buildings. Figure 5 highlights the results.

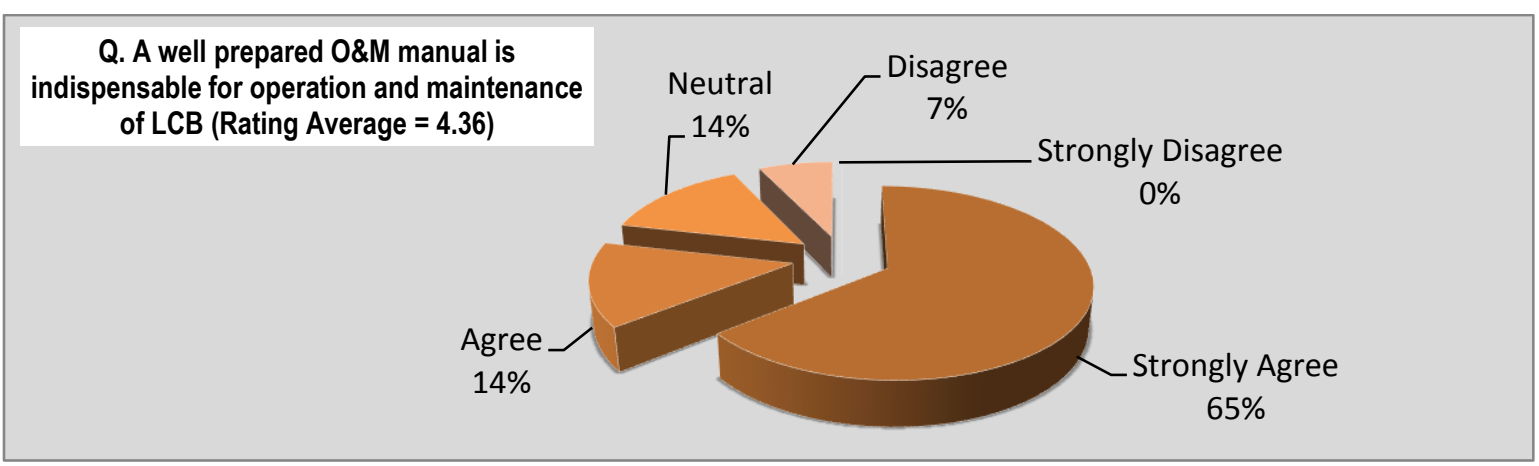

Figure 5: Participants' Opinion about the Indispensability of O\&M Manuals in the Operation and Maintenance of Low Carbon Buildings (Hard Copy Survey)

The rating was done on a scale of $1-5$, where 1 is 'strongly disagree' and 5 is 'strongly agree'. A rating average of 4.36 was returned. A total of $79 \%$ of the respondents agreed that the O\&M manual is an indispensable document for LCBs, while only $7 \%$ disagreed and $14 \%$ were neutral. Despite the disappointing outcome of the O\&M manual regime in the UK, participants in the hard copy survey who are mostly facilities managers; professionals involved with the day-to-day running of LCBs strongly believed that properly prepared O\&M manuals are indispensable for the running of LCBs. This therefore calls for decisive efforts on how to improve on the O\&M manual regime in the UK. 
The interviewees were also asked; 'Considering the disappointing outcomes of O\&M manuals, do you think it is still a necessary document for low carbon buildings'? 100\% of them believed the O\&M manual remains a needful document for the effective and efficient operations of buildings with new technologies. Comments from some of the interviewees are:

- "Very necessary!" (Interviewee 002).

- "I think it is definitely a useful thing to have, whether it helps you do the maintenance, it will definitely help you to find spare parts and that kind of stuff" (Interviewee 004).

\subsection{The Way Forward for O\&M Manual in LCBs}

This section examines the way forward for the O\&M manual; how the dented reputation which O\&M manual has attracted to the industry can be repaired; how O\&M manual can be made an effective tool that is capable of ensuring maintainability and efficient operation and maintenance. Results gathered through interviews, online and manually circulated hard copy surveys returned eight (8) recommendations from the respondents on the way-forward for O\&M manual regime in the UK.

\subsubsection{Integrating the O\&M Manual Process into the Design Process}

Interview results indicated that $60 \%$ of the interviewees were of the opinion that if O\&M manual process is brought in to the design process, it could enhance the quality of the manual. This question was however not part of the original intended interview questions, but emanating from the comments of one of the interviewees;

"I think you need someone who understands management and facilities management to come in at design phase and oversee that kind of knowledge transfer process and for them to assemble a manual" (Interviewee 002).

Following the strategy of inductive coding described by Marks and Yardley (2004), which involves drawing themes from the raw data itself, it became necessary to make further probe with subsequent interviewees and the surveys. So the other $40 \%$ of interviewees who were interviewed earlier were not asked this question. In essence, $100 \%$ of the interviewees who were confronted with the question agreed that it will be good practice to bring the O\&M manual process into the design process.

The online survey also returned $100 \%$ of respondents agreeing and strongly agreeing to the opinion that bringing the O\&M manual drafting process into the design process is capable of enhancing the quality of O\&M manuals in the UK. The result is summarised in figure 6. 


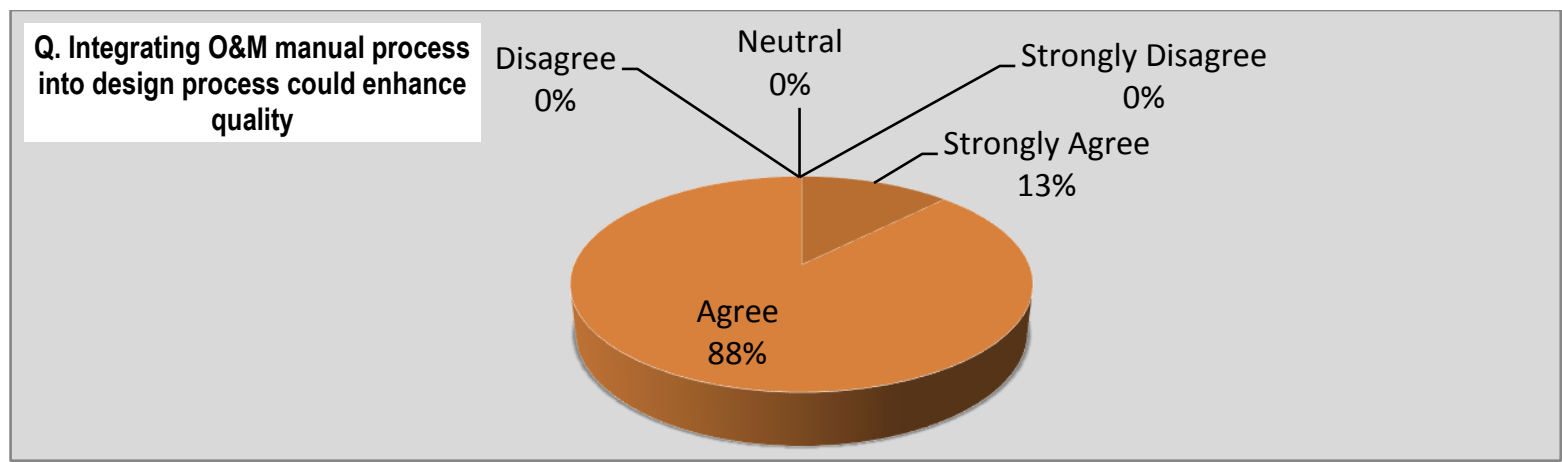

Figure 6: Integrating O\&M Manual Process into Design Process (Online Survey)

Figure 7 shows the result from the hard copy survey which returned $93 \%$ affirmation that bringing O\&M manual process into the design process is capable of ensuring that designers think through maintenance when designing. Only $7 \%$ of the respondents were neutral and none disagreed with the postulation.

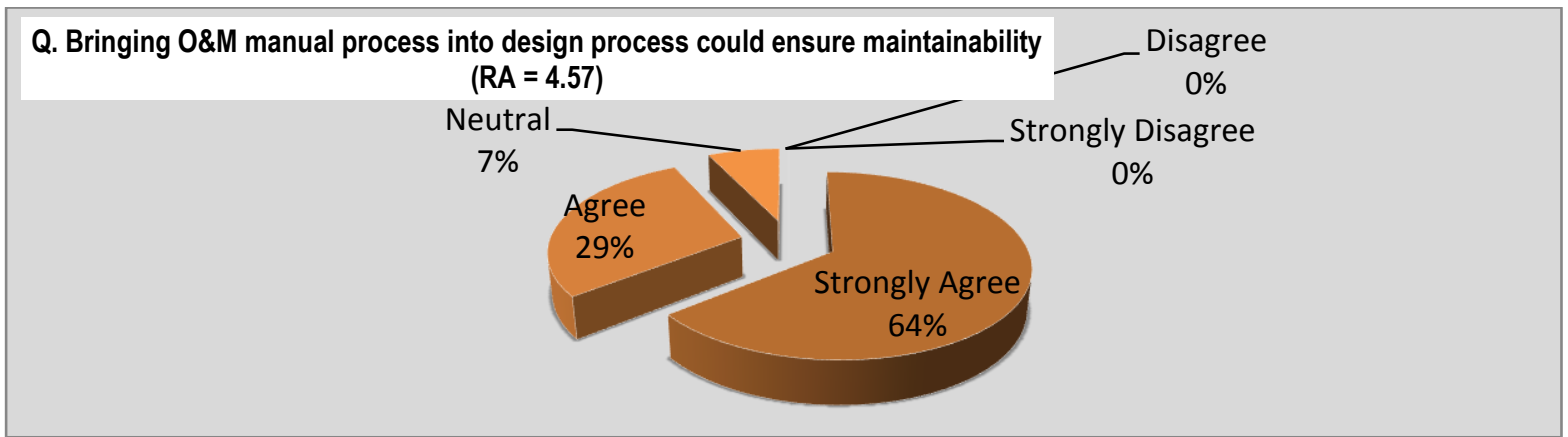

Figure 7: Integrating O\&M Manual Process into Design Process (Hard Copy Survey)

Also a web advert by Denaploy, a specialist O\&M manual authoring company, with the caption; 'Making Manuals that Work', corroborated these results. It noted that O\&M manuals preparation should start at the beginning of the project, and that if you leave it to the last minute just as the handover looms, then it will always be a second best. Interestingly, this is coming from people who are experienced in the preparation of O\&M manuals (Denaploy, 2013).

\subsubsection{Involving O\&M Manual Specialists from the Design Stage}

During the interviews, one of the interviewees opined that involving maintenance staff in making imputes to design may result in stifle in innovation and technological advancements in design. However, other interviewees (60\%) believed that involving personnel who are involved and/or are experienced in building operation and maintenance management will improve the design output. Another interviewee comments: 
"I don't think the design team necessarily understands. They do care but it is not their primary concern how the building operates after construction. So you need some with a good understanding of facilities management I would say" (Interviewee 002).

So both statements were tested with the online survey as well. Results show that $63 \%$ of respondents expressed neutrality to the statement that Involving O\&M specialist will stifle innovations (see figure 8). Only $12 \%$ agreed and $25 \%$ says involving O\&M specialists will not cause stifle in innovations.

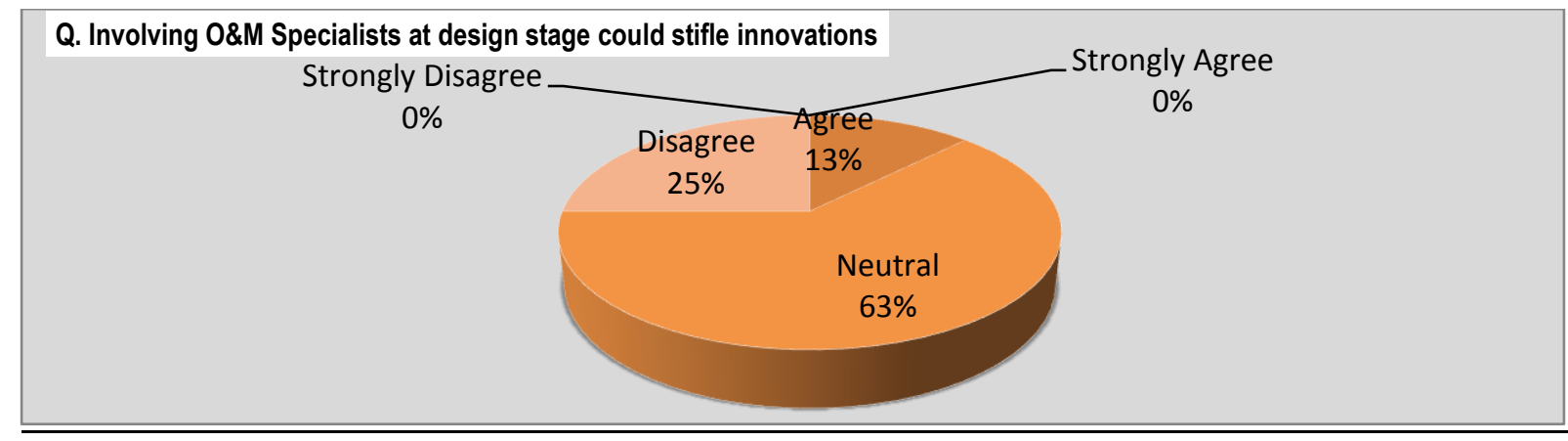

Figure 8: Involving O\&M Specialist Could Stifle Innovations (Online Survey)

Whereas, twisting the question to read; 'If the O\&M manual specialists become part of the design team, this could contribute to architects giving more attention to operation and maintenance challenges' was put to respondents and $87 \%$ agreed, the remaining $13 \%$ were neutral, with none disagreeing (figure 9). So it can be concluded that rather than causing stifle in innovation and technological advancement, involving O\&M manual specialists in the design process will help to improve design maintainability.

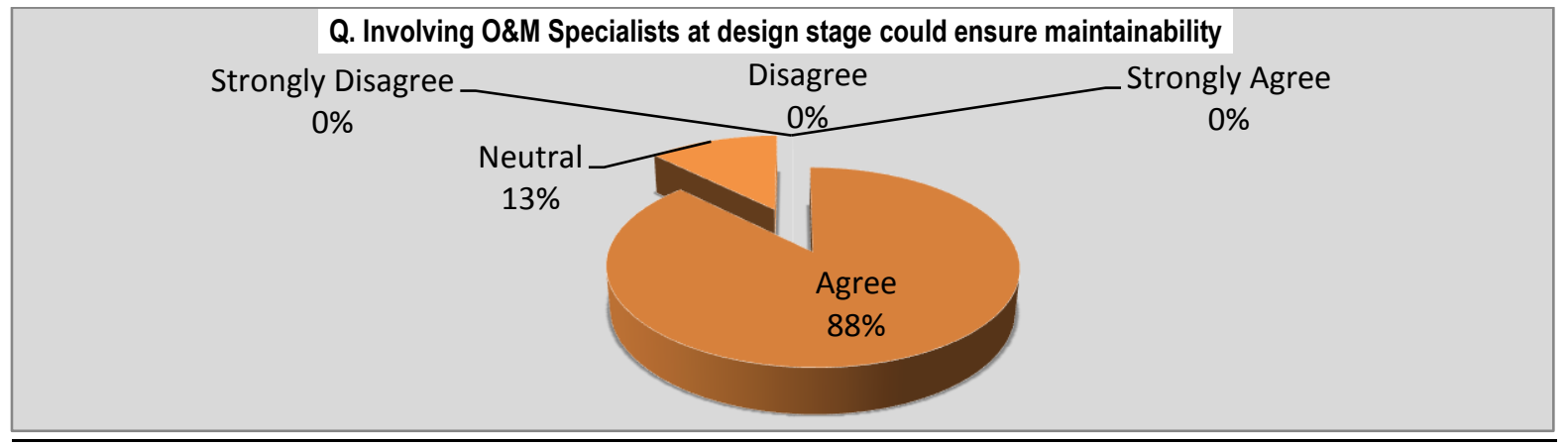

Figure 9: Involving O\&M Manual Specialist Could Ensure Maintainability (Online Survey)

\subsubsection{Transferring Responsibility of Collating/Authoring to the lead designer}

It seems to be that the original intention of the Committee on Building Maintenance of the Ministry of Public Building and Works of August 1965 was that the O\&M manual was to be produced by designers. MPBW (1970) noted in its preface that one way of ensuring that clients and maintenance managers possess good knowledge of the buildings they occupy and for which they are responsible is 
'for designers to produce O\&M manuals as part of their commission'. However, as noted in previous sections and from comment by interviewees and survey respondents, the current practice is that the responsibility appears to be that of the contractors. Also the CDM Regulations 2007 places responsibility on the CDM Coordinator to collate and compile the Health \& Safety File, which normally incorporates the O\&M manuals (CDM Reg. 2007 Approved Code of Practice, Regulations 17).

In this study therefore, respondents in the online survey were required to rate the extent of their agreement/disagreement with the statement; 'If responsibility of collating the O\&M manual is transferred to the lead designer, it will help to strengthen the link between designers and operators of buildings'. Here also majority ( $87 \%$ ) of the respondents were indifferent and $13 \%$ strongly agreed, as shown in figure 10 . Although none disagreed, but $13 \%$ is a very small percentage and cannot be used as a basis for affirming that designers be responsible for collating and compiling O\&M manuals..

Q. Transferring responsibility of collating the manual to the lead designer would help to strengthen link between designers and operators of buildings

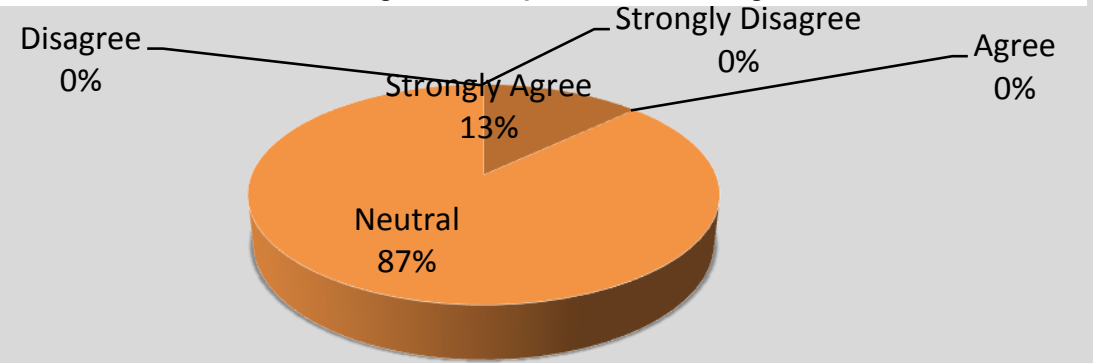

Figure 10: Transferring Responsibility of Collating O\&M Manuals to the Lead Designer (Online Survey)

The interviewees were equally sceptical about transferring responsibility for collating the manual to the lead designer. A comment from an interviewee refers:

"I think you have a fair point about making him responsible, but I'm concerned about doing it through legislation or statutory control, that's quite a big step. ..., irrespective of who handles it, my preference is that it is not done as an after-thought. .... I think as the process goes on, it's a good idea that the O\&M manuals grow with the building, so that people understand what they are getting" (Interviewee 003).

Conclusion here is that whoever collates the manual is irrelevant, what is relevant is that it should be started from inception of the design stage. CIRIA (1999) corroborates this position. It noted that various professionals involved in the design and construction process are well placed to lead the preparation of an O\&M manual; either a senior member of the design team or the main contractor or a specialist author. 


\subsubsection{Develop a first Draft of the O\&M Manual at the Design Stage}

Current practices of O\&M manual delivery as discussed in section 4.3 shows that preparation of the first draft of the manual is usually commenced from the construction or during handover and commissioning stage of the project. The final draft is then handed in while the building is in operation or during handover/commissioning and in few cases, still within the construction period. Respondents were also asked to indicate the extent of their agreement or disagreement with the statement that 'It will be good practice to make the first draft of the O\&M manual at the design stage. The results shown in figure 11 indicate that $75 \%$ of the respondents accented to the affirmative, while the remaining $25 \%$ were neutral. None disagreed.

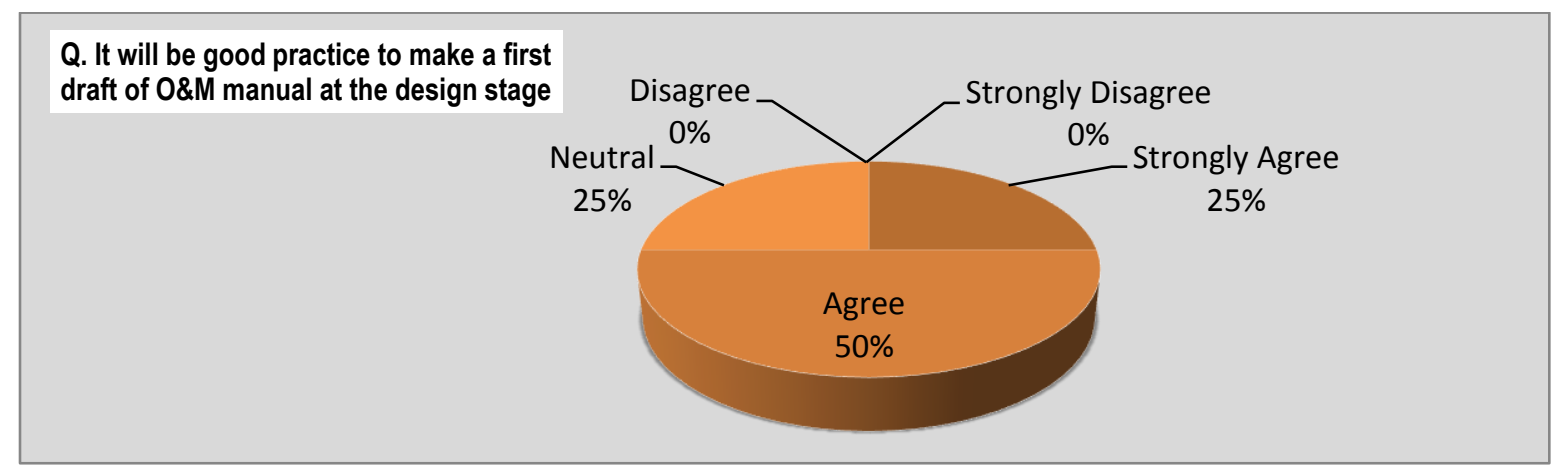

Figure 11: It will be Good Practice to Make a First Draft of O\&M Manual during Design (Online Survey)

\subsubsection{Providing Information in User-Friendly Formats}

Analysing the general comments on the manual survey using the thematic content analysis approach indicates that over $50 \%$ of respondents proposed that the information in the O\&M manual be provided in alternative user-friendly format. A few of the comments include:

* "Provide information in other user-friendly formats"

* "Too much detailed high level specific specs; this cannot easily be read by nontechnical staff. Should be simple".

* "Web enabled soft copies with hyper-links are much easier to use".

* etc.

Another comment by an interviewee reads thus:

“... people's answer to digital form I find frustrating, because what they tend to do is to give you a PDF, you can't search a PDF. That's not clever technology. My view is that you need to put it on a $C D$. If you go to a garage with your car and you say you want to change a broken light bulb and you type in broken light bulb and it reads the $C D$, and says where is it? You type in break light and it gives you the number, that's what you want for your car. If I try to find what that broken light bulb is in the O\&M manual, it will take me twenty minutes or more and I might not find it. .... That is poor in my view" (Interviewee 003). 
All these comments are clear indications that facilities managers are desirous of O\&M manual, not only in a web format, but also in an easy to comprehend form by a non-technical building owner or building user. Majority of the respondents to the manual survey are facilities manager, Interviewee 003 is also a facilities manager with a background in Architecture.

\subsubsection{Separate Technical Details from Users' Operation and Maintenance Guide}

Similarly, in the manual survey, under general comments about any improvements desired for the O\&M manual regime in the UK, about $70 \%$ of the respondents opined that there should be a separation between the actual operation and maintenance guide and the technical cum manufacturers' literature. Some of the comments include:

* "Separate actual operator manual and maintenance regimes, etc. Hazard/emergency procedure, etc."

* "Remove manufacturers' promotional literature"

* "I think O\&M manuals should have 2 sections. First of all there is a requirement for all the technical data that is essential. However, there should also be the 'easy to use layman's guide' which is easier for maintenance staff to understand".

\subsection{CONCLUSIONS}

This paper has discussed the current practices with respect to the O\&M manual regime in the UK; noting that it attracts poor repute to the construction industry, and often seen as an unnecessary burden to the contractors who are trying to complete the build. They are rarely made to be fit for purpose, yet they are documents that are intended to enable efficient operation, maintenance, repairs and act as link between the project design team and the client as well as his maintenance team to their mutual benefits. Some of the factors affecting the poor repute O\&M manuals attract to the construction industry, as discovered from the study indicates that most O\&M manual:

- lack appropriate details that could aid effective operation and maintenance

- are just compilations of manufacturers' manuals

- $\quad$ are prepared just for the purpose of meeting legal requirements and not fit for purpose

- the time of delivery does not aid maintainability

- in most cases are not transferred to the actual operators in case of lease or re-sale of property 
- The Time of delivery does not give clients opportunity of alternative choice of materials, equipment and/or technology

- Often poor quality

- contain too many unnecessary details and technicalities that make them too difficult to be useable

- $\quad$ are often not user-friendly

The study also shows that despite the prevalent poor repute with the O\&M manual, it is still seen as a potential document that could be harnessed to bridge the gap between designers and operators of LCBs, and as an indispensable tool for the effective management of LCBs, if properly prepared. The study also proposes ways of ensuring a properly prepared O\&M manual. They include:

- Integrating the O\&M manual Process into the design Process

- Involving O\&M manual specialists from the design stage

- Developing a first draft of the manual at the design stage

- Separating technical details from Users' Operation and Maintenance Guide', and putting them in searchable, user-friendly formats

- Provide reference to other physical examples where the technologies introduced, may have been successfully used.

These conclusions therefore call for the need for a change in the way O\&M manuals are being prepared, particularly for LCBs, and by extension, a change in the whole design and construction process, where the conclusions reached in this study could be integrated.

\section{REFERENCES}

Adshead, J. (2011). The Quest for Sustainable Buildings: getting it right at the planning stage. In J. Adshead (Ed.), Green Buildings and the Law (pp. 76 - 93). London: Spon Press.

AHDA - Affordable Housing Design Advisor. (n.d.). Step 19. Create an operation and maintenance manual for project. Retrieved march 17, 2010, from Affordable Housing Design Advisor: http://www.designadvisor.org/

Aronson, J. (1994, Spring). A Pragmatic View of Thematic Analysis. Retrieved December 11, 2012, from The Qualitative Report: http://www.nova.edu/ssss/QR/Backlssues/QR2-1/aronson.html

Avis. (2011). World Carbon Reduction Targets. Retrieved Nonember 24, 2011, from Avis: http://www.avis.ca.za/main.aspx?ID=1634 
Birchall, S. (2011, December 09). Post Occupancy Evaluation - The challenge of a 'greener' future. Retrieved December 25, 2011, from BSRIA Blog: http://blogs.bsria.co.uk/2011/12/09/postoccupancy-evaluation-the-challenges-of-a-greener-future/\#comments

Blacker, J. (1994). Maintenance Manual and their Use. In E. D. Mills (Ed.), Building Maintenance and Preservation: Guide for Design and Management (2nd ed., pp. 244-276). London: Butterworth Heinemann.

BRE - Building Research Establishment. (2009). Sustainability in the Built Environment: An introduction to its definition and measurement. (C. Atkinson, A. Yates, \& M. Wyatt, Eds.) Watford: IHS BRE Press.

BSRIA - Building Services Research and Information Association. (2007). A BSRIA Guide: Handover, O\&M Manuals, and Project Feedback - A toolkit for designers and contractors (BG 1/2007). (P. Hastings, K. Pennycook, \& R. Bunn, Eds.) BSRIA.

BSRIA - Building Services Research and Information Association. (2011, July). A BSRIA Guide: Building Manuals and Building User Guides guidance and worked examples (BG 26/2011). (J. Harris, A. Wilson, \& S. Deramchi, Eds.) BSRIA.

Burnard, P. (1991). A Method of Analysing Interview Transcripts in Qualitative Research. Nurse Education Today, 11, 461 - 466.

Cabinet Office. (2011, May). Government Construction Strategy. Available at: https://www.gov.uk/government/uploads/system/uploads/attachment_data/file/61152/Govern ment-Construction-Strategy_0.pdf: Cabinet Office.

Carbon Trust. (2012). Closing the Gap. London, UK: The Carbon Trust.

CIRIA - Construction Industry Research and Information Association. (1999). CIRIA C507: Operation and Maintenance Manuals for Buildings: a guide to procurement and preparation. London: CIRIA.

Denaploy. (2013). O\&M Manuals for Main Contractors M\&E Technical Authoring. Retrieved July 29, 2013, from Denaploy Internet: http://www.denaploymanuals.co.uk/common_pitfalls_in_preparing_oandm_manuals.page

Henson, J. L., \& Lamberts, R. (2011). Building Performance Simulation for Design and Operation. Abingdon, Oxen: Spon Press.

Julien, H. (2008). The SAGE Encyclopedia of Qualitative Research Methods. SAGE Publishers.

Malekzadeh, M., Bouchlaghem, D., \& Wheeler, A. (2011). Application and Management of Environmental Technologies in UK Schools: A case study. SET 2011, 10th International Conference on Sustainable Energy Technologies. Istanbul Turkiye.

Marks, D. F., \& Yardley, L. (2004). Research Methods for Clinical and Health Psychology. SAGE Publishers.

Masoso, O. T., \& Grobler, L. J. (2010). The dark side of occupants' behaviour on building energy use. Energy and Buildings, 42, 173 - 177.

MPBW - Ministry of Public Buildings and Works. (1970). Maintenance Manuals for Buildings. London: Her Marjesty Stationary Office.

Nana, G., \& Stokes, F. (2012). A View to the South: Potential Low Carbon Growth Opportunities for the Southern Region Economy. Wellington - New Zealand: berl - Business and Economic Research Ltd.

People4Business Ltd. (2010). Freelance Technical Author. Retrieved September 29, 2010, from people4business recruitment: http://www.people4business.com/seller-242451.htm 
Piper, J. E. (1999). Operations and Maintenance Manual for Energy Management. New York, USA: M. E. Sharpe, Inc.

RIBA - Royal Institute of British Architects. (2009a). Climate Change Toolkit: 01 Climate Change Briefing. London: RIBA.

RIBA - Royal Institute of British Architects. (2009c). Climate Change Toolkit: 03 Principles of Low Carbon Design and Refurbishment. London: RIBA.

Schwandt, T. A. (2007). The SAGE Dictionary of Qualitative Inquiry. (3rd, Ed.) SAGE Publishers.

Seeley, I. H. (1987). Building Maintenance (2nd ed.). London: Macmillan Press.

Seeley, I. H. (1996). Building Economics (4th ed.). New York: Palgrave.

Silva, N. D., Dulaimi, M. F., Ling, F. Y., \& Ofori, G. (2004). Improving the Maintainability of Buildings in Singapore. Building and Environment(39), 1243 - 1251.

Yu, Z., Fung, B. C., Haghighat, F., Yoshino, H., \& Morofsky, E. (2011). A systematic procedure to study the influence of occupant behaviour on building energy consumption. Energy and Buildings, 43, 1409 - 1417. 